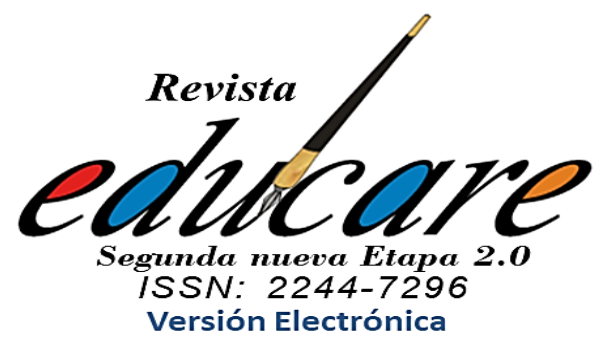

Volumen $25 N^{\circ} 3$ Septiembre - Diciembre 2021

(364-386)

\title{
APRENDIZAJES \\ PRODUCTIVOS, UN PROCESO \\ INTEGRADOR ENTRE LA \\ EDUCACIÓN Y EL \\ PATRIMONIO CULTURAL
}

Secretaria De Educación

Del Distrito-Bogotá

Colombia

Jhon Helmuth Avila Ortiz*

Ingrid María Sandoval Martínez**

ORCID: https://orcid.org/0000-0003-4447-2803

\section{Contacto}

*E-mail: helmuth316@ gmail.com

**E-mail: ingrid.sandoval@ cenda.edu.co
Recibido:

23-08-2021

Aceptado:

28-10-2021
EDUCATION AND CULTURAL HERITAGE PRODUCTIVE LEARNING, AN INTEGRATING PROCESS BETWEEN 


\section{Introducción}

En la localidad 5 de Usme en Bogotá (Colombia), durante la ejecución de obras públicas en el año 2006 con el pasar de una máquina retroexcavadora emergen del suelo vestigios arqueológicos asociados a la población nativa del actual altiplano cundiboyacense, denominados Herrera y Muisca. Esta situación es generada por la intervención adelantada en el proyecto "Nuevo Usme" de la constructora "Metrovivienda", una empresa del Distrito de Bogotá (hoy denominada ERU-Empresa de Renovación Urbana) orientada al desarrollo y transformación del territorio.

A raíz de este hallazgo arqueológico, algunos habitantes de la zona rural y urbana de Usme se unen para defender este patrimonio cultural y solicitan a las entidades locales y distritales los estudios correspondientes, basados en argumentos legales y acciones colectivas para detener las obras y evitar la destrucción de los vestigios arqueológicos. Así surge una movilización social que contribuyó a gestar prácticas patrimoniales dirigidas a preservar este sitio.

Específicamente desde el ámbito de la educación se realizan acciones que buscan fundamentar sobre lo patrimonial, permitió entender el contexto histórico del pasado local para las nuevas generaciones, es por ello, que en el colegio Atabanzha surge el proyecto "Aprendizajes Productivos a través de la Comprensión Etnocultural" (PAPCE) donde a lo largo del tiempo se han realizado diversas experiencias pedagógicas en torno al patrimonio arqueológico y cultural del sector.

En un inicio el proyecto contemplo desde la asignatura de Lengua Castellana la diversidad lingüística en Colombia, y encontró además otras temáticas como: la riqueza patrimonial tangible e intangible del sector, la diversidad cultural aborigen y sus saberes. Sin embargo, en el aula de clase surge un interrogante: ¿Cómo hacer para que un estudiante de nuestra ciudad lleno de diversas informaciones globalizadas se interese por el patrimonio material e inmaterial que posee Colombia, su capital y más aún su localidad?, ya que es necesario desde diversas asignaturas hacer énfasis en la cultura patrimonial partió desde lo particular a lo general, para que los niños, niñas y adolescentes que se encuentran en las aulas de clases valoren y enriquezcan la gama cultural autóctona de Colombia, y contribuyan así al patrimonio de la nación. 
Para contribuir a resolver las indagaciones de los estudiantes sobre el patrimonio cultural material e inmaterial de la localidad se inicia con un proceso de consulta sobre los primeros habitantes de la comunidad indígena que predominó en el sector, apuntando todo hacia el tema "Muisca", por ser la cultura aborigen originaria de la localidad. Se consultaron mitos e historias de Usme (mito de Saguamanchica, Usminia, Nemequene, entre otros). Lugares de la localidad "topónimos" con nombres ancestrales, encontrando un gran número de lugares con nombres muiscas, y luego se analizaron los nombres de otros sitios dentro de la ciudad y departamentos.

De esta manera el proyecto de "Aprendizajes Productivos a través de Comprensión Etnocultural", se encuentra apoyando el tema patrimonial de la localidad. Es cuando se da inicio al proyecto el cual tiene como objetivos: El rescate y reconocimiento del patrimonio ancestral tangible e intangible indígena muisca de la localidad. Promover talleres que tengan aprendizajes provechosos, útiles para los estudiantes y a su vez promover saberes autóctonos. Relacionar desde una perspectiva ancestral diferentes proyectos institucionales exigidos desde la Secretaria de Educación de Bogotá (SED) como: PRAE, PILEO, Danza, Música, Club de Astronomía, programa de Inclusión con niños de discapacidad cognitiva leve.

En los procesos de reconocimiento, indagación y recolección de información sobre la localidad que se llevan a cabo en el proyecto "PAPCE" se encontró información relevante sobre el espacio colindante de la institución educativa, ya que Usme es un espacio agrícola por antonomasia, en donde confluyen muchas variables dentro de lo rural y el poco espacio urbano que lo componen. Se representan, con firmeza, las expresiones culturales ancestrales endémicas de cada uno de sus habitantes que son manifestadas en los lugares que conforman esta localidad.

Se resaltan los recursos a nivel retórico y de acción por parte de algunos habitantes, los cuales son fundamentales en la defensa del territorio frente a instituciones de carácter oficial y privado. En estas entidades sus intereses se inclinan hacia la transformación del espacio natural sin importar el daño provocado en los mismos, al ignorar a sus moradores, atacando su economía y sus bases de producción agrícola. Todo esto es un soporte importante para el abastecimiento distrital y regional debido a su riqueza hídrica y agropecuaria. 
La localidad de Usme es un espacio periférico densamente poblado como producto de un proceso de conurbación qué, desde el año 1950, generó un efecto de metropolización con la ciudad de Bogotá. Sin embargo, en la actualidad mantiene su carácter rural que cuenta con un alto porcentaje de su extensión territorial. Usme es la segunda localidad con más áreas rurales —18 500 hectáreas—, de las cuáles 2 104,6 son de suelo urbano y 901,9 se proyectan como terreno de expansión. Este es un lugar heterogéneo en donde en su parte urbana convergen personas de todos los lugares del país. Este espacio ha tenido fuertes transformaciones desde su etapa de ocupación indígena, bajo el régimen colonial y en la conformación de la República. Esta condición de cambio se mantiene actualmente.

$\mathrm{Su}$ mayor función y sustento económico es el agrícola, que inicia desde antes de la colonia y se acentúa con el modelo latifundista denominado "la hacienda" mantenida durante los siglos XIX y XX y que se negó a desaparecer del sector a pesar de las fuertes transformaciones en el espacio geográfico. Esta condición prevaleció hasta el año 1980. El paisaje cultural actual conserva algunos rasgos característicos de estos periodos, los cuales se preservan en la memoria de sus habitantes originarios.

Con lo anterior, algunos habitantes de carácter urbano y rural, se organizaron para realizar propuestas y mitigar la expansión urbana que estaba afectando la memoria histórica local. Para ello, dichos moradores conformaron mesas de trabajo frente a los planes de ordenamiento territorial (POT), planteando alternativas para mantener la condición rural de la localidad de Usme. En donde se proponía que dicha expansión urbana no se manifestara de forma agresiva con el campesinado y el medio ambiente (Pacto de bordes urbano-rural). Propuestas que, según narraciones orales de la población, no fueron escuchadas, lo que repercutió que ese imaginario ancestral de algunos habitantes se fuera atenuando.

La historia de una posible expansión urbana - que cada vez era inminente - cambia, cuando en el año 2006, en uno de los terrenos comprados con la finalidad de ejecutar la construcción de la urbanización "Nuevo Usme", surgen algunos artefactos arqueológicos en el proceso de remoción de tierra para la adecuación del terreno. Estos hallazgos aumentaron en número con el pasar de los días, lo que hizo encender las alarmas en la comunidad residente frente a la importancia de retomar sus referentes ancestrales con más fuerza.

De esta manera surgen acciones colectivas en las que los repertorios discursivos y de acción se presentaron como una oportunidad comunitaria de defender el territorio de esa 
violencia simbólica que traía la urbanización. Las acciones institucionales y privadas avanzaban en la trasformación del territorio sin importar la relevancia que dicho hallazgo representaba a nivel científico y académico. El hallazgo, además de ser una prueba fehaciente del pasado prehispánico del sector, brindó herramientas para que los habitantes se motivaran en argumentar en torno a la existencia de un territorio que había sido habitado por comunidades indígenas, en este caso, del pueblo Muisca. Además de valorar, dada su gran importancia histórica y actual para la región, la conservación de este espacio rural de producción agrícola que es primordial en el sustento económico de los pobladores del lugar.

Según los pobladores a este hallazgo se le atribuye una gran importancia a la que denominan "La gran biblioteca prehispánica". A esto se suma la incidencia que, por su ubicación estratégica, permite comunicar a Bogotá con los Llanos Orientales y la Orinoquia (esto por ser de paso obligatorio debido a las condiciones de relieve geográfico que no permiten fácilmente el acceso). Esta condición favoreció para que en determinados valles de Usme se formaran asentamientos humanos que permitían el intercambio de mercancías provenientes del sur del país, así como la construcción de experiencias compartidas entre las diversas comunidades autóctonas que habitan estas regiones.

En el caso del hallazgo arqueológico "Hacienda El Carmen", algunos pobladores de la zona rural y urbana, con limitados recursos y oportunidades para incidir en las políticas que se generaron sobre el territorio de Usme en materia de expansión urbana, encuentran en los vestigios arqueológicos una oportunidad para accionar colectivamente. Esto, utilizando marcos culturales en defensa de la ruralidad ante la expansión urbana; justificando así sus razonamientos sobre mantener vigente un territorio en riesgo de pauperización y rechazando la modificación de dicho espacio para la urbanización.

Dentro del contexto proyecto se desarrollan actividades con base en la situación mencionada anteriormente. La primera actividad que se realizó el PAPCE en el marco del fue con los docentes, directivas y algunos estudiantes líderes de la jornada tarde, una salida al hallazgo arqueológico muisca, la cual tuvo como objetivo informar sobre la riqueza patrimonial de este territorio y así contar con su colaboración en la difusión sobre dicho tema logrando así una introducción sobre la parte ancestral Muisca de la institución. 
Figura 1. Foro educativo, Proyecto Aprendizajes Productivos a Través de la Comprensión Etnocultural

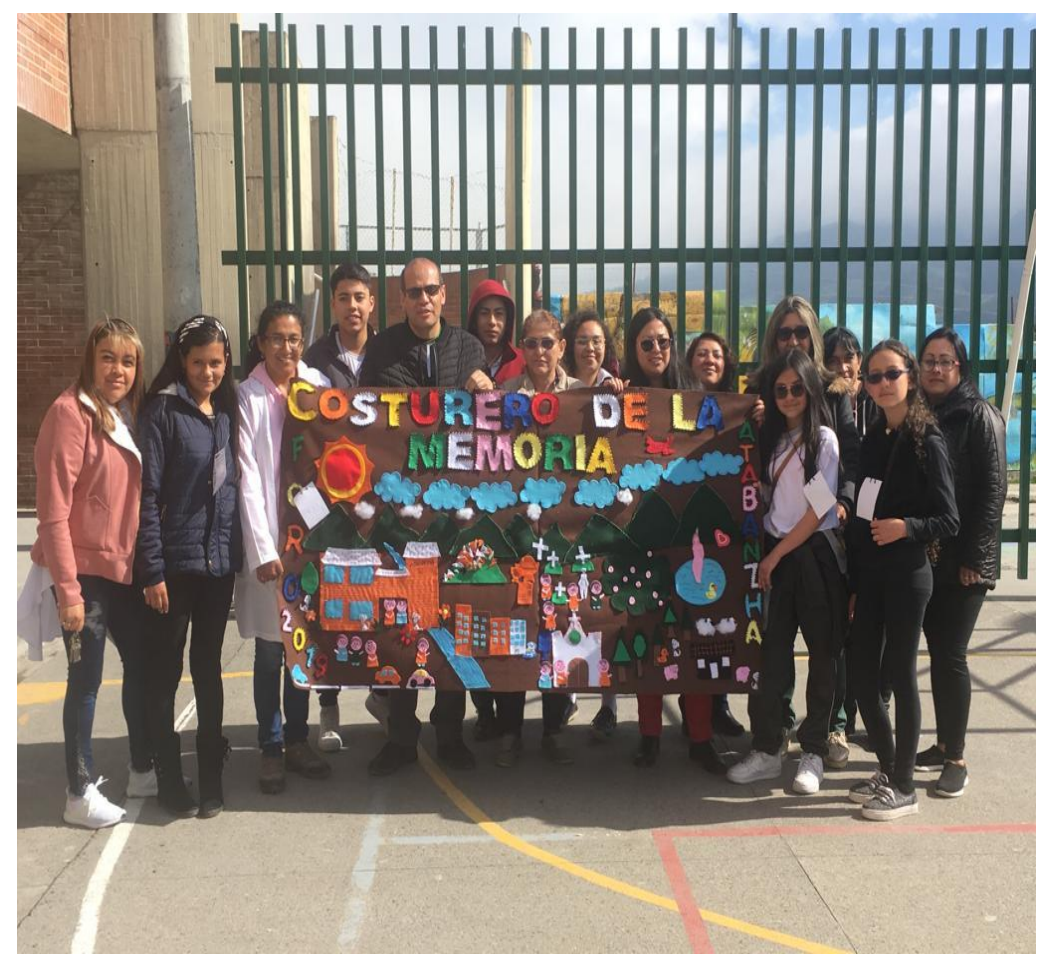

Fuente: autor, año 2019

\section{Argumentación teórica}

En las actuales discusiones sobre el patrimonio se encuentran diferentes perspectivas: políticas, mediáticas y sociales, en donde la población busca aportar en la preservación de los espacios tradicionales. Generando que este tema se convierta en un factor de interés colectivo que promueven protagonismos en el que aparecen agentes sociales patrimoniales que necesitan del manejo de un discurso adecuado para incidir y conducir la colectividad.

El concepto de patrimonio es entendido como aquello que comprende los elementos que identifican distintos grupos humanos, tales como: los lugares, la tradición oral, la música, la alimentación, el vestuario y todo aquello que distingue la soberanía de los pueblos del mundo.

patrimonio son los bienes que poseemos o los bienes que hemos heredado de nuestros ascendientes. Lógicamente, patrimonio es también todo lo que traspasamos en herencia. Entendemos que se trata fundamentalmente de objetos materiales como 
una casa, unos libros, unos utensilios o un trozo de tierra. De forma parecida podemos referirnos a derechos y obligaciones, es decir a cosas menos tangibles. Incluso podemos hablar de patrimonio en un sentido menos materialista, más abstracto o más espiritual. (Ballart \& Tresserras, 2001, p. 11).

En este caso el patrimonio cultural de Usme comprende la importancia de preservar y mantener vigentes las expresiones y pensamientos que manifiestan los grupos humanos a partir de sus costumbres representadas en los restos de sus antepasados. Para la UNESCO, el patrimonio será entendido como la herencia cultural propia del pasado de una comunidad, mantenida hasta la actualidad y transmitida a las generaciones presentes $\mathrm{y}$ futuras (UNESCO, 15 noviembre de 1989).

Desde otro punto de vista, también podría interpretarse como herencia colectiva cultural del pasado: nuestro pasado, el pasado de una comunidad, el pasado de toda la humanidad, que conecta y relaciona a los seres humanos del ayer con los hombres y mujeres del presente, en beneficio de su riqueza cultural y de su sentido de identidad. La herencia cultural o legado cultural es un activo útil a las sociedades. El derecho de las generaciones que la reciben es disfrutar plenamente de sus valores, adquirir el deber de traspasarlas en las mejores condiciones a las generaciones venideras. Con lo anterior, la educación no es ajena al reconocimiento del patrimonio y de la apropiación del mismo.

En el sistema educativo colombiano se evidencia un proceso de implementación de contenidos temáticos en las diversas asignaturas que obedecen a las competencias y derechos básicos de aprendizaje que propone el Ministerio de Educación Nacional (MEN). En ese proceso de enseñanza-aprendizaje se observan algunos puntos que hablan de la diversidad cultural, memoria, territorio y contexto, de manera superficial, y que son abordados por las áreas de humanidades como los son las Ciencias Sociales y Lengua Castellana. Aunque es de advertir que la palabra-concepto: patrimonio, no se ve reflejada puntualmente en la organización curricular.

Por otro lado, es clave mencionar que, en dichas asignaturas, especialmente Ciencias sociales, se sigue abordando temas como la Historia de Colombia de una manera tradicional. En el trato de estas temáticas no se evidencian variaciones sobre la investigación e innovación. Son abordadas de manera general, donde falta un acercamiento 
puntual frente a la relación con un verdadero reconocimiento del entorno y su ámbito comunitario.

Además de los contenidos temáticos exigidos desde el MEN, como ejemplo en la reorganización curricular por ciclos, se hace dispendioso realizar un proceso de reconocimiento patrimonial en los planes de estudio. Situación que conlleva que las propuestas educativas se presenten solo en el papel, o máximo, en un discurso abstracto sin acciones concretas. Entonces, el proceso de enseñanza-aprendizaje de lo patrimonial permanece en manos de los museos y para un grupo poblacional reducido.

La política estatal en lo referente al patrimonio cultural de la Nación tendrá como objetivos principales la salvaguardia, protección, recuperación, conservación, sostenibilidad y divulgación del mismo, con el propósito de que sirva de testimonio de la identidad cultural nacional, tanto en el presente como en el futuro" (Legislación y normas generales para la Gestión, Protección y Salvaguardia del Patrimonio Cultural en Colombia, Ley 1185 de 2008, 12 de marzo).

Es importante democratizar el acceso a los bienes culturales, además de conservar y adecuar nuestra riqueza patrimonial. Este punto es clave para valorar la diversidad cultural, donde cada vez los espacios son plurales y diversos. "Educar para la tolerancia, aprecio y respeto al diferente, debe ser parte constitutiva de cualquier agenda que quiera formar ciudadanos para el mundo globalizado". (Unesco, Patrimonio y cultura local en la escuela, Santiago de Chile, 2002).

Por ello, es importante hacer de los bienes patrimoniales un recurso provechoso para la educación, donde el factor social del bien común sea fundamental. A su vez, la voluntad política es importante para la preservación que genera, desde el ámbito educativo, las competencias y los derechos básicos de aprendizaje que contribuyan al conocimiento del mismo.

En el caso específico del hallazgo arqueológico de la "Hacienda El Carmen", algunos docentes accionaron en torno al mismo, lo que contribuye así a los repertorios de acción y de discurso formalizados en los diversos proyectos de aula. Algunos de estos incidieron en la comunidad educativa ampliamente, otros se quedaron en espacios reducidos; sin embargo, dichos esfuerzos, se sumaron al proceso de análisis, concientización, divulgación y preservación de este espacio. 
Uno ejemplo de las prácticas patrimoniales en torno al ámbito pedagógico fue el cambio de nombre de la institución educativa, que paso de llamarse "Valle de Cafam" a "Atabanzha IED” el cual significa mujer de danza y alegría que habitaba en la laguna de los tunjos, laguna sagrada de los Muiscas, a nivel linguístico el vocablo hace parte de la lengua muisca donde Ata es el número uno, y banzha es bondad en la oscuridad, dando el significado de dicho vocablo: primeros en bondad.

Posteriormente para cerrar el proceso del cambio de nombre, se realizaron dos salidas pedagógicas, primero; con el cuerpo docente y directivo, y segundo con un grupo de estudiantes a dicho sitio para mostrar la magnitud del lugar. Sería entonces una secuencia de salidas que involucran a toda la comunidad educativa para poder realizar una reproducción de la información.

Las comunidades educativas que accionaron en torno al hallazgo arqueológico, plantean que dicho espacio patrimonial es muy importante para la comunidad, ya que es de ayuda en los diversos procesos de enseñanza-aprendizaje. Esto debido a que las instituciones educativas del sector están integradas por población de estratos socioeconómicos correspondiente al nivel 1 y 2, donde la igualdad de oportunidades a nivel formativo es mínima en comparación con otras localidades de la ciudad.

El desplazarse a espacios fuera de las instituciones educativas para enseñar historia, diversidad cultural, entre otras temáticas, requiere de recursos económicos con los que no siempre se cuenta y que son reducidos para el sector. Por ello, el espacio de un futuro museo in situ, sería un gran potencial académico que brindará oportunidades a los docentes de la localidad para la enseñanza de sus asignaturas.

Este proyecto establece cómo incide la escuela en una pedagogía reivindicante de la cultura, la memoria e identidad, toma como punto de partida los valores tradicionales endógenos, tanto ancestrales como campesinos de la región, difundiéndolos de tal forma que se divulgue el reconocimiento de los mismos. A grandes rasgos el PAPCE busca socializar, valorar y reivindicar la identidad de la localidad que, de acuerdo con sus gestores, está a punto de ser olvidada. Situación que sería una gran pérdida para el ámbito patrimonial del sector: "El aprendizaje del patrimonio puede servir para asentar el concepto de ciudadanía y evitar la génesis de desigualdades sociales” (Hernández, 2012, p. 649). 


\section{Descripción de la experiencia}

El proyecto "Aprendizajes productivos a través de la comprensión Etnocultural" lleva en institución trece años y viene desarrollando actividades que se enfocan hacia la recuperación de la memoria ancestral e indígena, con el fin de fortalecer y salvaguardar en la comunidad educativa y su entorno los valores tradicionales ancestrales y campesinos, presentes en los grupos familiares. Esto se realiza a partir de procesos de formación cultural que permitan la apropiación, valoración y afirmación de la identidad muisca y campesina del sector, fomentando así la similitud social nutrida desde el territorio, lo que refuerza el interés hacia la alteridad y la otredad que se refleja en las demás asignaturas, incorporando los saberes patrimoniales al aula brindando de esta manera la oportunidad de ampliar los diversos campos del conocimientos de una forma innovadora donde se asocia el pasado con el presente.

En el contexto del proyecto, la metodología implementada es a través de conversatorios, talleres, salidas de campo, relatos históricos, recuperación de la tradición oral de la localidad y la región, juegos tradicionales, oficios tradicionales, huerta escolar, artes plásticas, entre otros; todos ellos con el propósito de dar a conocer a sus habitantes la historia del lugar. Estos esfuerzos buscan fundamentar una mayor cohesión social, así como generar nuevas prácticas territoriales, tanto de los antiguos moradores como de los que legan desde otros sitios. 


\section{Figura 2.}

Intercambio cultural. Proyecto Aprendizajes Productivos a través de la Comprensión Etnocultural, visita de la comunidad Siriano del Vaupés a la institución educativa Atabanzha.

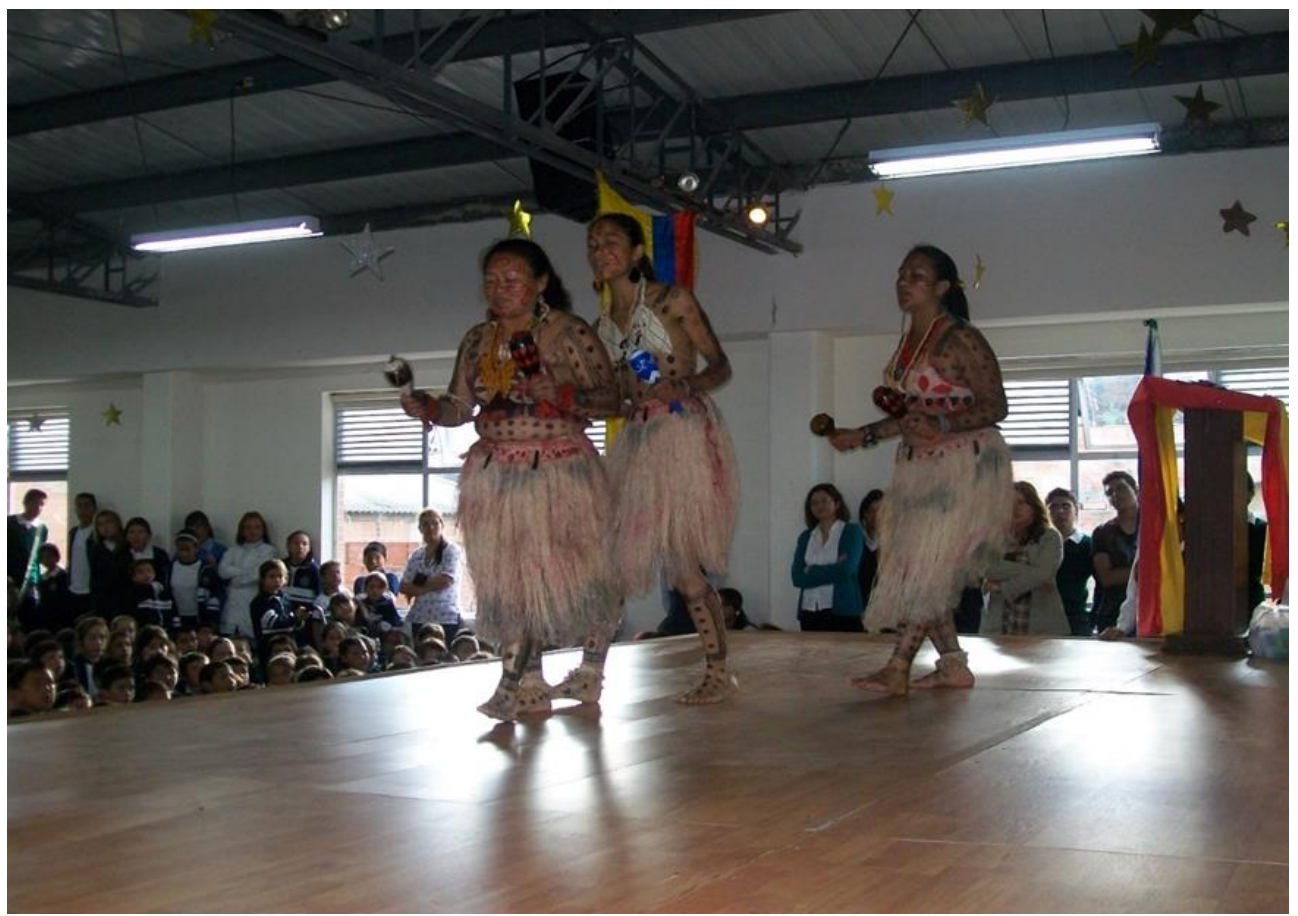

Fuente: autor, año 2018

Este proyecto pedagógico también ha comprendido el intercambio de saberes con comunidades indígenas de la región (Cabildo de Sesquile, Tubu Marimasa-Sirianos del Vaupés), que se suman a las de la población campesina del sector. Los niños aprenden diversas enseñanzas por parte de estas comunidades, tales como tejidos en lana y mostacilla, talleres de palabras en lengua muisca, cultivos de alimentos tradicionales, entre otras prácticas. Este proceso se llevó a cabo con el objetivo de rescatar usos y costumbres que con el paso del tiempo han sido olvidadas por la población urbana del sector y que son importantes para el fortalecimiento del patrimonio en la localidad.

Las prácticas pedagógicas en el ámbito de lo patrimonial, en este caso en torno al hallazgo arqueológico y el territorio en general, han sido propuestas y desarrolladas por la gestora del proyecto: la docente Ingrid María Sandoval y que hace parte de la Mesa de 
Patrimonio Usmeka. Esta agrupación es una organización comunitaria que surge en el año 2007 y que tiene como propósito defender las características ancestrales de la región. La gestora y docente no solo es profesora del sector, sino habitante del mismo, y ha visto como la conurbación ha terminado con veredas y haciendas, perjudicado el medio el ambiente, la flora y la fauna de la zona. Además de estas circunstancias, también ha sido testigo del daño a otros vestigios arqueológicos en la zona los cuales se encontraban en espacios que han sido urbanizados: piedras con pictografía, petroglifos y vestigios ceremoniales que tenían formas para pagamentos, (algunas de ellas de tamaños considerables) que se vieron afectadas por este proceso. Esos lechos rocosos fueron explotados, algunos por parte de los habitantes en la construcción de sus casas, otros por las empresas extractoras de materiales para construcción, pues la localidad de Usme tiene en su parte norte un complejo minero que ha funcionado durante décadas.

La profesora Ingrid Sandoval ha llevado el patrimonio a la escuela y la escuela al patrimonio; pues en las actividades que ha propuesto se han realizado ejercicios donde el patrimonio tangible e intangible es clave. Dentro del patrimonio intangible se cuentan las visitas por parte de las comunidades indígenas al plantel educativo, para lo cual el intercambio cultural es importante. El dialogar con sabedores de las etnias fomenta el reconocimiento, respeto y valoración de la diversidad étnica. Proceso formador en las nuevas generaciones donde identificar y reconocer el valor de esos saberes tradicionales, fundamentan en el país una sana convivencia, una tolerancia hacia las diversas formas de vida, sociales y culturales, pues serán ellos el futuro del país. (Ortuño, Molina, Sánchez y Gómez 2012).

En cuanto al patrimonio tangible se puede aludir a la realización de diversas salidas de campo, las cuales se han ejecutado con dinero público administrado por la institución educativa, tal como lo contempla las normas de administración pública. Los rubros empleados provienen de la Secretaría de Educación de Bogotá y otros han sido otorgados mediante el programa "Apoyos Concertados del Ministerio de Cultura". Estos estímulos han sido dirigidos para la sensibilización, promulgación y valoración de la riqueza patrimonial y cultural tanto en el colegio como para la localidad en general. Algunas de estas prácticas pedagógicas consisten en salidas al páramo de Sumapaz, a la laguna sagrada 
de los Tunjos, así como para explorar la importancia de la cuenca del río Tunjuelo y su afectación en la parte baja de la localidad

\section{Figura 3}

Proyecto Aprendizajes Productivos a Través de la Comprensión Etnocultural, salida pedagógica Museo Nacional.

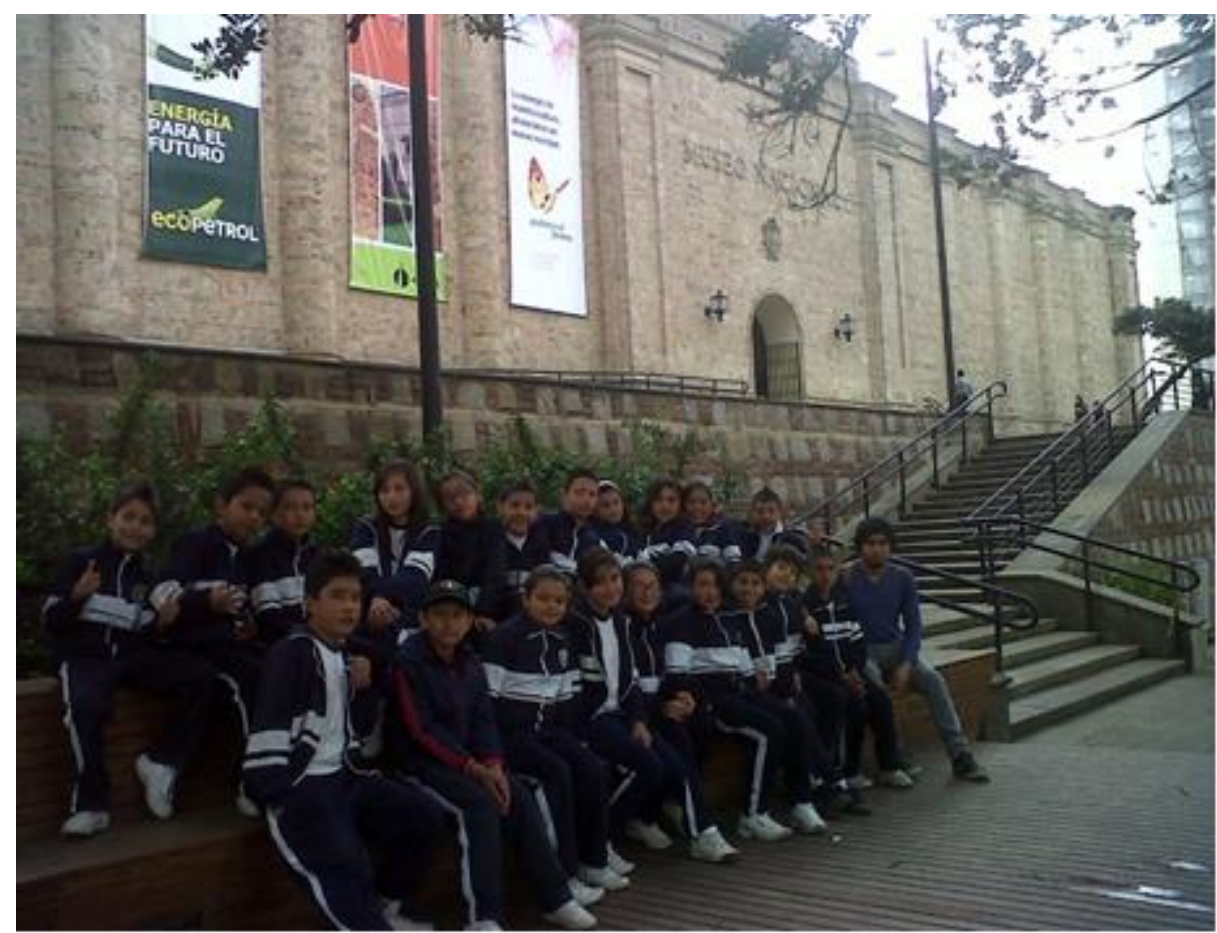

Fuente: autor, año 2012

El intercambio de saberes autóctonos con población campesina y los estudiantes, es una actividad importante, pues Usme es una localidad rural en su extensión geográfica, esto contribuye al reconocimiento del contexto inmediato en que está inmerso la institución educativa. Además, la ejecución de talleres de siembra, talleres de trabajo con arcilla, visitas al espacio del hallazgo arqueológico "Hacienda el Carmen" y los lechos rocosos de la finca Santa Helena (aledaña al "Hacienda el Carmen"), las visitas al laboratorio arqueológico de la Universidad Nacional de Colombia, en donde se encuentran los vestigios en custodia, permiten ver la diversidad de instituciones, organizaciones y comunidad en general que se encuentra en torno al patrimonio.

Las salidas a los Museos: Nacional y de Oro para ampliar los conocimientos sobre las comunidades indígenas en general, además de contrastar los artefactos del hallazgo con 
los custodiados por los museos, permite reflexionar sobre el valor histórico y patrimonial de mismos y la necesidad de salvaguardar los que se encuentran a nivel local. Para incrementar el valor se salvaguarda patrimonial se trabaja con el material didáctico "Maletas pedagógicas" proporcionado por el Museo del Oro, y que permite trabajar en el aula de clase con réplicas miniatura, para de esta forma, identificar con mayor énfasis las comunidades indígenas existentes en Colombia.

\section{Figura 4}

Proyecto Aprendizajes Productivos a Través de la Comprensión Etnocultural, visita pedagógica Museo Nacional.

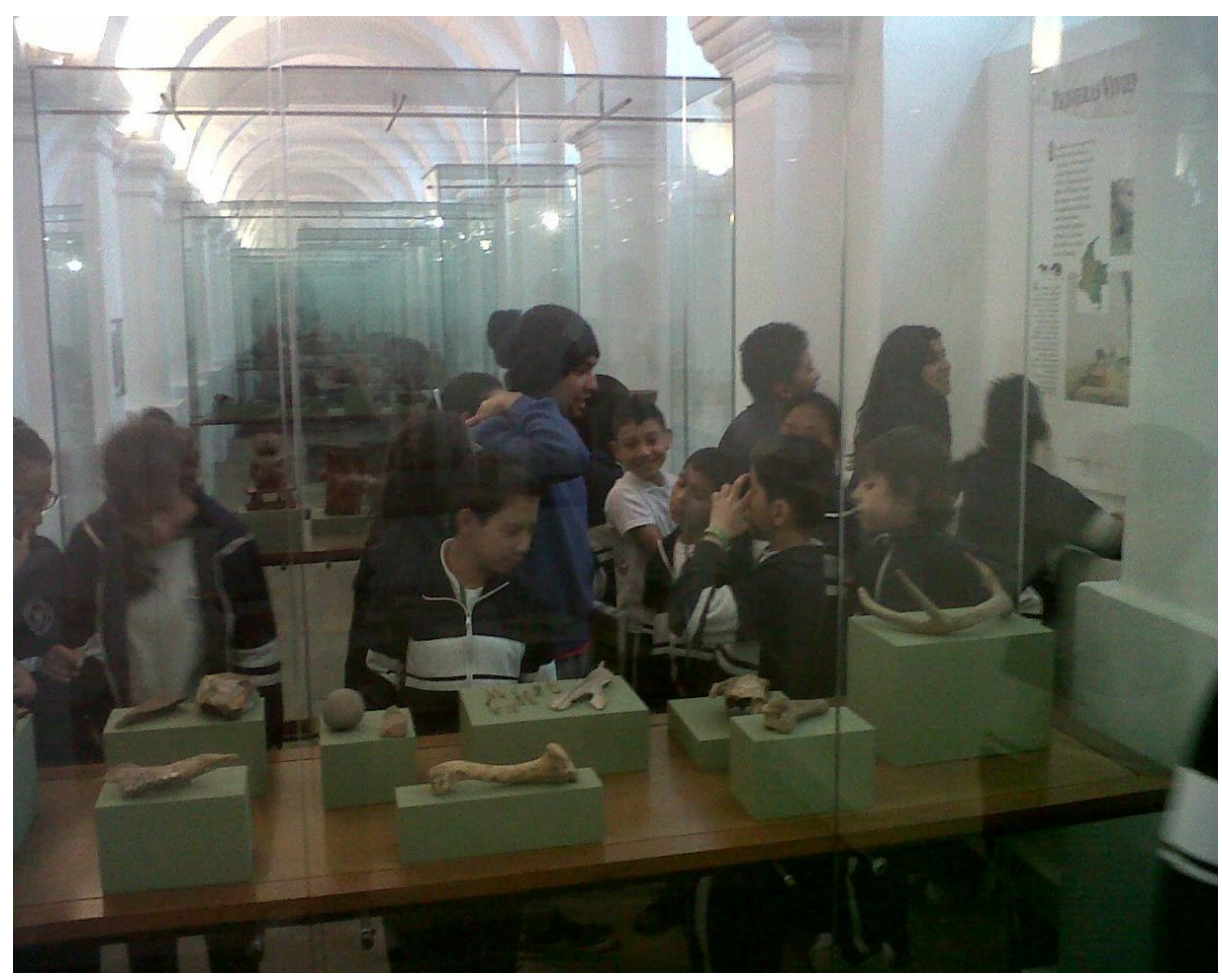

Fuente: autor, año 2012

Otra actividad ejecutada en el proyecto son las salidas a la laguna de Guatavita. Estas se realizan con el fin de que los estudiantes conecten la localidad con la región. Se busca que relacionen el hallazgo arqueológico de la "Hacienda el Carmen" con toda su explicación sobre la población de los muiscas, con el parque ecológico y arqueológico "Laguna de Guatavita", además de ubicar los conocimientos previos de su contexto con el lugar visitado en donde se encuentra presente la relación mitológica entre las lagunas. Además, los estudiantes han tenido la oportunidad de asistir al cabildo muisca de Sesquilé, 
entrar al templo ceremonial, escuchar algunos representantes de dicha comunidad y ver cómo estas comunidades hacen resistencia para no desaparecer.

Cabe resaltar que dicho proyecto ha tenido varios reconocimientos y alcances. A continuación, se nombrarán los más significativos. El primero de ellos fue una salida de campo -otorgada por la empresa de turismo Aviatur- a la Isla Gorgona en el año 2009 en la que un grupo de estudiantes tuvieron la oportunidad de conocer dicho patrimonio natural e histórico de Colombia. El segundo reconocimiento fue el cambio de nombre de la Institución en el año 2010, que pasó de llamarse "Institución educativa distrital Valles de Cafam" por IED "Atabanzha". Este vocablo muisca busca hacer alusión al patrimonio local. El tercer reconocimiento fue el apoyo monetario durante varios años del programa "Apoyos concertados" del Ministerio de Cultura. Otra distinción para este proyecto fue la invitación a diversos espacios académicos y culturales a nivel local y distrital. Por último, se reconoce esta iniciativa pedagógica como referente a nivel local, por ser un proceso que nace de la defensa del hallazgo arqueológico "Hacienda El Carmen".

\section{Discusión de los resultados}

El proyecto ha permitido durante su tiempo de ejecución hacer una fusión entre la cultura, la pedagogía y el patrimonio en la comunidad educativa. Ejemplo de ello es el cambio de nombre institucional, además de contemplar diversas visitas por parte de comunidades indígenas y la ejecución de proyectos en institucionales transversales que han promovido la sensibilización en diferentes espacios sobre la importancia del territorio, la memoria, la ruralidad, el hallazgo arqueológico y la tradición oral. Todo este impacto ha fomentado el respeto y la valoración interiorizada de dichos procesos para que sean transmitidos hacia los núcleos familiares y de la comunidad en general. Es decir, que el estudiante sea una persona integral, forjado en el respeto hacia los elementos patrimoniales del sector y de otros sitios donde también existen este tipo de factores.

Para ello, el proyecto promueve procesos de formación cultural, difusión e intercambio, comunicación y organización de eventos fundados en una pedagogía que permita el rescate y apropiación de valores culturales endógenos. Todo esto, parte de la base que es posible construir tejido social y así formar sujetos más críticos con respecto a su entorno, capaces de transformar e incidir sobre su territorio colectivamente en un 
proceso en donde, como indicará Freire (2011) "nadie libera a nadie, ni nadie se libera solo (...), los hombres se liberan en comunión".

El proyecto entonces brinda una visión significativa desde la perspectiva patrimonial de memoria e identidad. Los pueblos indígenas y campesinos preservan sus memorias, pues este proceso brinda identidad: "el sentido histórico (es decir, el sentido identitario) se construye desde los objetos hasta el paisaje. Esta suerte de referentes empíricos no son nada diferentes a la concreción de la memoria social (estructurada por la historia) en un espacio social" (Zambrano \& Gnecco, 2000. p. 184).

Esto contribuye a dar fortaleza al individuo para entrar en un mundo globalizante sin olvidar sus raíces. Pero para ello, debe haber una concientización, el reconocimiento de la condición de ser indígena está atravesado por un proceso de identificación colectiva, tanto dentro del mismo grupo como hacia el exterior. Se trata de consolidar una alteridad basada en la pertenencia a un grupo social poseedor de una diferencia cultural sustancial y, en muchas ocasiones, esencial. Pues si esto no fuese de esta manera, verían su memoria con vergüenza, hasta el punto de olvidarla para entrar al mundo "moderno".

Por ello, la memoria juega un papel significativo al ser una combinación indisoluble en el campo de las expresiones de las sociedades tradicionales que no están del todo alejada de nuestra visión. Esto se debe a que la memoria y el patrimonio se relacionan y están presentes mediante el registro y la conservación que nos permiten guardar imágenes, documentos, audios y conocimientos que forman parte de nuestra identidad cultural. Un pueblo sin memoria está condenado al "olvido", entendido esto como la falta de todo, puesto que sin ella no sería factible la conservación de conocimientos para transmitir formas de cultura. Al no poder hacerlo no tendríamos identidad y no podríamos reconocernos como parte de un todo, finalmente, no podríamos relacionarnos con el mundo que nos rodea (Repetto, 2006).

Por otro lado, algunas instituciones educativas de la localidad se han pronunciado sobre el tema del hallazgo arqueológico y se han preocupado por contribuir en la preservación cultural que lo rodea. Mediante manifestaciones artísticas, instituciones como el Colegio Eduardo Umaña, Francisco Antonio Zea, el Instituto Pedagógico Arturo Ramírez Montufar, el Colegio Miguel de Cervantes, Colegio Rural Olarte, han contribuido en la valoración y protección patrimonial. 
Estos procesos en la zona de Usme han sido de importancia para la población campesina y líderes que buscan rescatar el patrimonio local cultural, arqueológico, ambiental, geográfico y museístico, lo cual ha llevado a manifestar, en diferentes escenarios, la necesidad de una cátedra patrimonial en Usme. Este grupo de maestros, que han accionado dicho ámbito de forma individualizada, en el año 2021 se han organizado creando la "Red de Maestros Patrimonio Usmeka".

\section{Conclusiones}

Todas estas acciones llevan a la comunidad a pensar en el papel fundamental de la formación académica desde las instituciones y la entrada en vigencia de la educación patrimonial, la cual se encuentre reflejada dentro de los planes de estudio lo que es parte fundamental en el rescate de la memoria colectiva desde una edad temprana en donde se reconozca el entorno y todo lo que en él manifiesta. "La educación constituye de este modo un camino básico para el debate y el esclarecimiento disciplinar. La construcción de estrategias elaboradas a partir de la adecuada formación docente y no docente, es el punto de partida para que los alumnos se conviertan en protagonistas del compromiso y la participación ciudadana" (Carbonari, 2008. pp 11).

Enfocar el conocimiento-escuela hacia la preservación es uno de los aspectos que se establecen como meta dentro del sistema educativo local; lo que atribuye a la formación temprana hacia la conservación de todo lo que implica el patrimonio y la concepción de la identidad: "la escuela tiene la tarea de la educación integral de los ciudadanos desde las edades más tempranas, de manera particular debe formarlos como personas que conocen y comprenden la historia nacional y local" (Reyes, Arteaga \& Jevey 2003, p.138).

En este sentido, el organismo desde un inicio ha puesto en práctica los valores sobre el rescate y cuidado de todas las manifestaciones patrimoniales pertenecientes a la zona y la importancia de las mismas; son todas estas fundamentales para poder entender las realidades sociales. 


\section{Figura 5}

Proyecto Aprendizajes Productivos a través de la Comprensión Etnocultural, talleres de tejido.

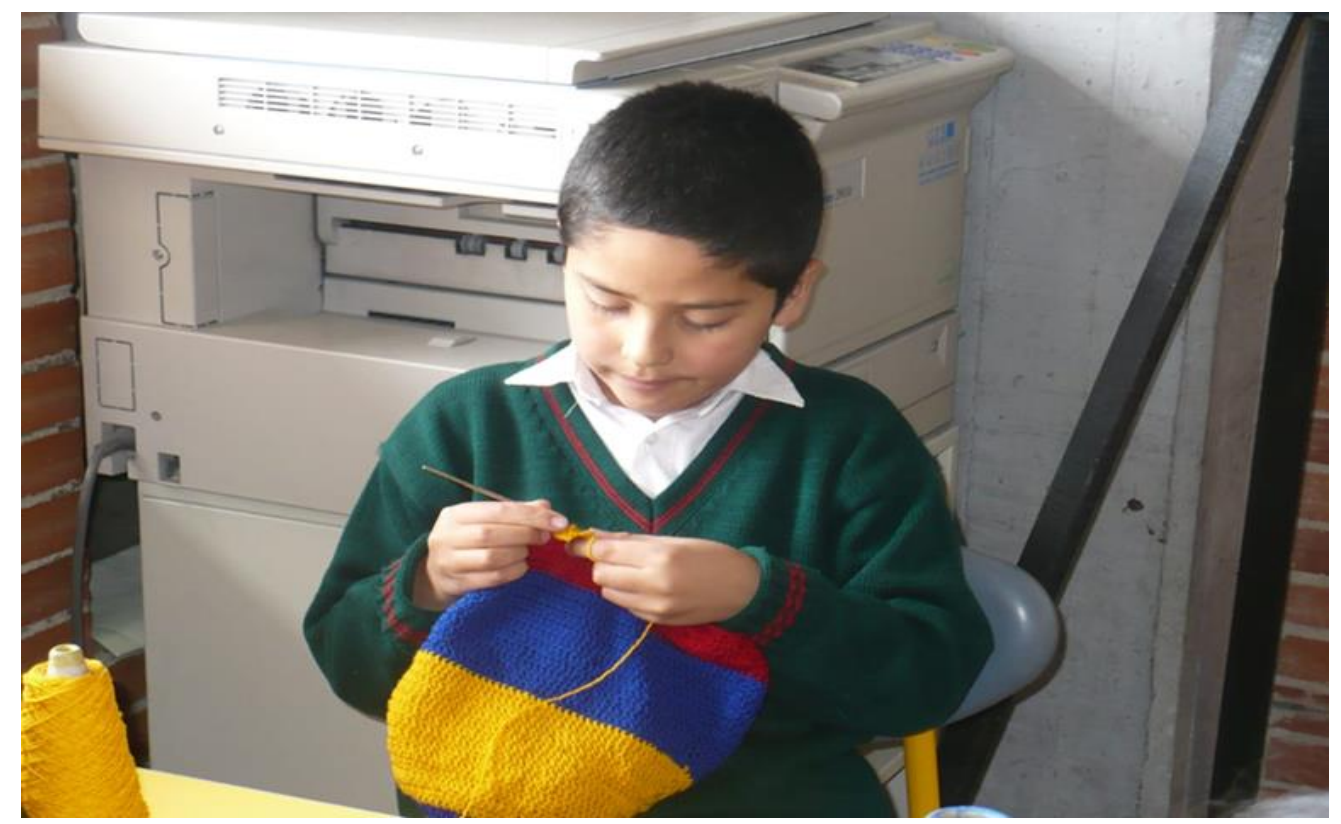

Fuente: Ingrid Sandoval, año 2011

Como lo indica Lozano (2013), reconocer el pasado, aprender a observar los restos materiales para leerlos, analizarlos e interpretarlos y educar la mirada para entender y comparar lo que se ve, son algunos de los objetivos que la formación en el patrimonio permite alcanzar en todos los niveles educativos. (p 7)

La implementación del proceso que realiza la docente Ingrid Sandoval ha permitido reflejar las carencias sobre el reconocimiento patrimonial, la incorporación de elementos históricos específicos de los grupos humanos que en un momento dado pertenecieron a Usme, su cronología, su modo de vida, usos y costumbres y lo que aún se conserva de ellos, simbolizados todos estos en la ruralidad que se mantiene a pesar de las adversidades.

Así mismo es importante hacer de los bienes patrimoniales un recurso provechoso para la educación, donde el factor social del bien común es fundamental. A su vez la voluntad política es importante para la preservación, generando así, desde el ámbito educativo, las competencias y los derechos básicos del aprendizaje que contribuyan al conocimiento del mismo. 
Es por ello que la educación y el patrimonio adquieren un valor fundamental, buscando que la dimensión simbólica del patrimonio no sea reducida y menospreciada, pues es gracias a la educación que se reconoce la variedad patrimonial en la zona. Lo que lleva a enseñar y a ubicar conceptualmente a las nuevas generaciones que se encuentran en torno al hallazgo arqueológico "Hacienda El Carmen", sobre la valoración significativa y preponderante del mismo. Todo lo que esto ha generado en recursos sociales, culturales y académicos, lo que fortalece así la colectividad en la gestión del mismo proceso al ser vital en una eventual patrimonialización.

\section{Figura 6}

Proyecto Aprendizajes Productivos a través de la Comprensión Etnocultural, elaboración mural, reconocimiento del patrimonio local.

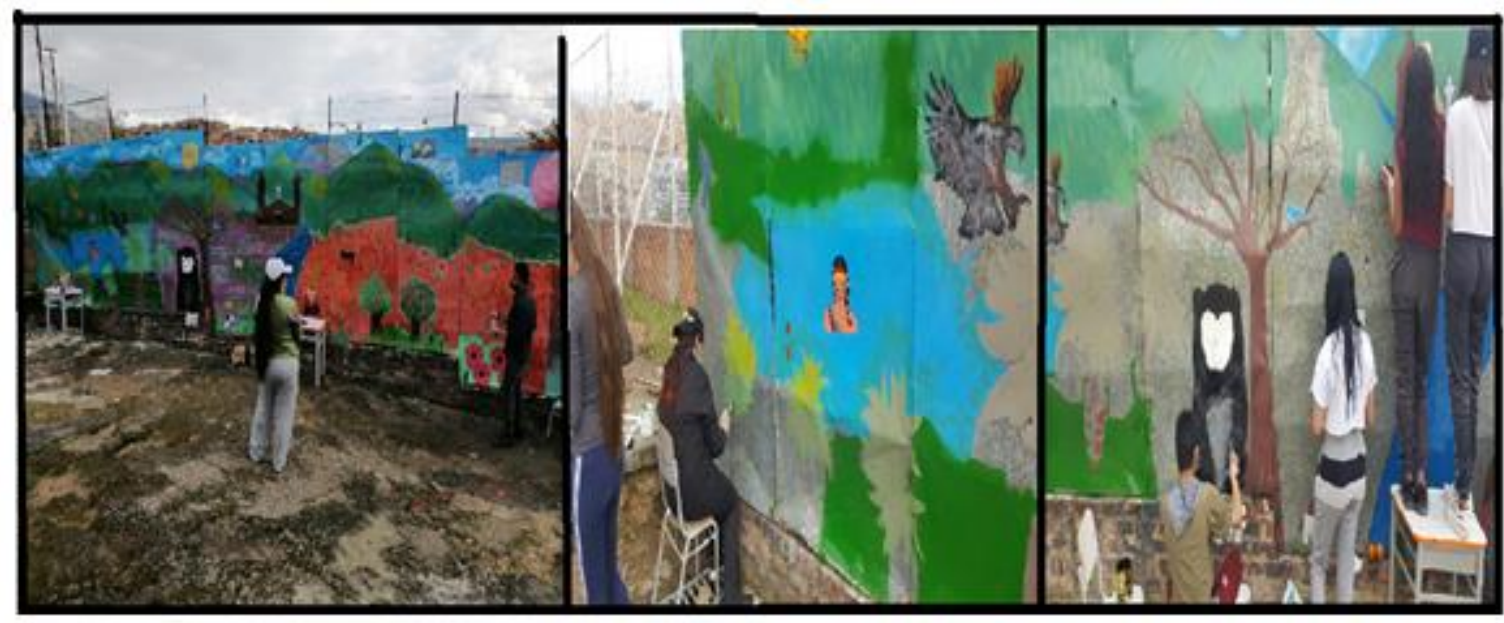

Fuente: Ingrid Sandoval, año 2021

\section{Reflexiones finales}

El hallazgo arqueológico "Hacienda El Carmen" ha influido en muchos de los procesos locales, colectivos e individuales, lo que ocasiono cambios en las perspectivas de habitar y vivir el territorio. Los sectores (educativo, económico, social, cultural y político) fueron convocados con el fin de conocer la situación real del espacio patrimonial y sus constantes afectaciones. Esto contribuyó al impulso de repertorios de acción y de discurso que se emplearon a través del tiempo por parte de los militantes hacia otros ámbitos. Ya no existía en la localidad un patrimonio arqueológico solamente, sino también un patrimonio cultural, académico, ambiental y geográfico. 
Por lo tanto, podemos plantear en el caso del hallazgo arqueológico 'Hacienda El Carmen" que las personas comprometidas con la causa se han instruido tanto de forma autodidacta como desde lo formal con títulos académicos, así los recursos sociales de las personas participantes en las acciones colectivas han arrojado espacios de reconocimiento y de apropiación desde diferentes ámbitos: sociales, culturales, ambientales, patrimoniales y educativos, donde todos trabajan en torno a dicho espacio.

El discurso necesita de un soporte de acción, de elementos que respalden dichas alocuciones en los diferentes escenarios de participación donde se complementen ambos. Así mismo, estos repertorios promueven los conceptos y percepciones de la escuela y los habitantes en general, hacia el territorio y el patrimonio. Por lo cual los colectivos, fundaciones e instituciones educativas, sumaron esfuerzos y llevaron a cabo actividades que salvaguardaron el patrimonio y la tradición. Eventos que aún se reflejan en actos culturales de diversas entidades pertenecientes a la localidad, fundamentando entonces una identidad y sentido de pertenencia al lugar, arrojando procesos identitarios.

Es así que los discursos patrimoniales influyeron en las prácticas pedagógicas, sociales y culturales de los participantes, ubicándose en espacios de investigación y académicos, por ejemplo, en el Instituto Distrital de Patrimonio Cultural (IDPC) y el Ministerio de Cultura. Además, genero impacto en algunos encuentros académicos, en universidades y colegios, lo que ha fortalecido con el paso del tiempo, el proceso de patrimonialización del hallazgo arqueológico "Hacienda El Carmen".

Por último, la educación es parte fundamental en el proceso de patrimonialización, los elementos académicos han contribuido a formar las nuevas generaciones y su orientación hacia la sensibilización del patrimonio cultural, arqueológico y ambiental local, resalta los valores históricos, ambientales, sociales y geográficos del sector. Enseñando el respeto hacia la diversidad cultural y de esta manera contribuir al fomento del desarrollo de la tolerancia y la disminución de la exclusión. Elementos que son necesarios para la construcción actual de país, formando futuros herederos del patrimonio desde diversas perspectivas que inicien un nuevo reconocimiento de lo rural y lo patrimonial. 


\section{Figura 7}

Proyecto Aprendizajes Productivos a Través de la Comprensión Etnocultural, salida pedagógica Páramo de Sumapaz.

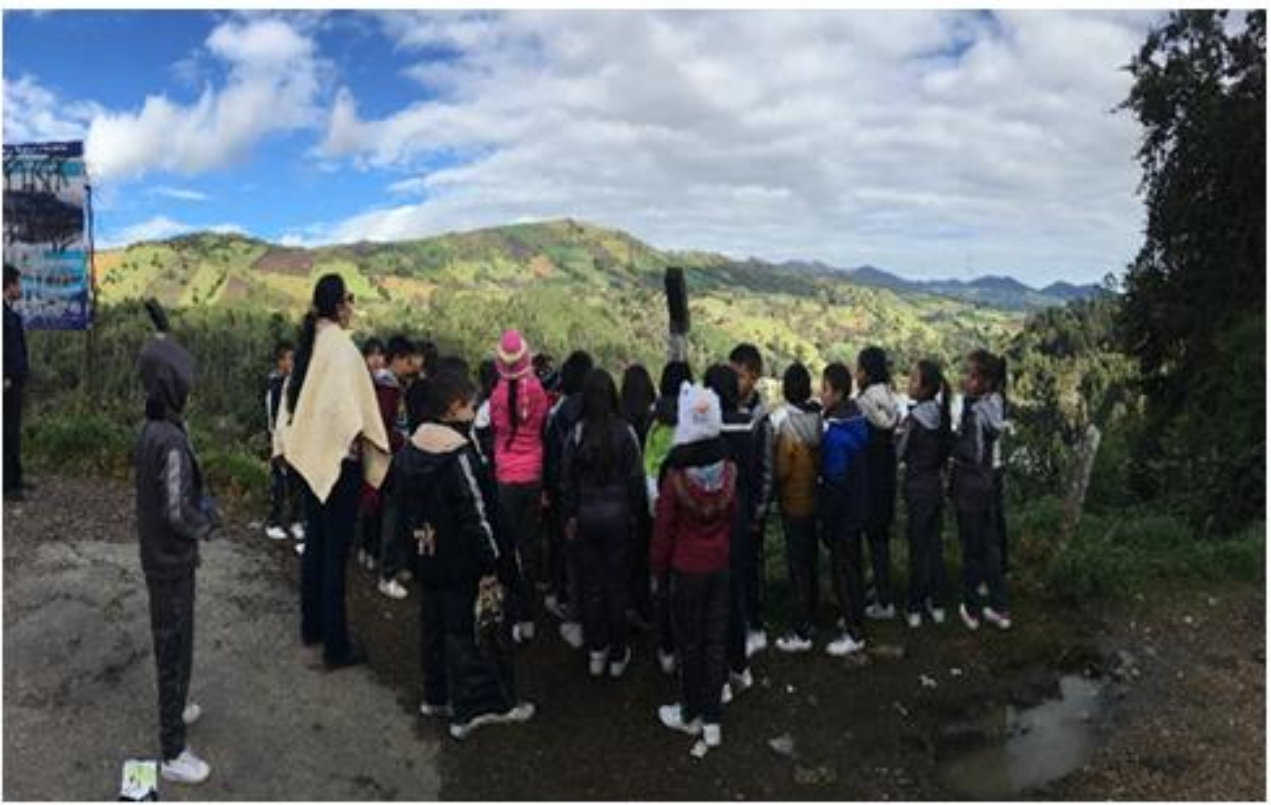

Fuente: autor, año 2019

\section{Referencias}

Ballart J. \& T, J. (2001) Gestión del patrimonio cultural, 5ta ed., Barcelona: Ariel, p. 11.

Carbonari, F.( 2008) Aproximación a la problemática patrimonio-educación. Prosecretaria de asuntos académicos, Argentina: Universidad Nacional de Plata. pp 10-21.

Freire, P. (1993). Pedagogía de la esperanza, un reencuentro con la pedagogía del oprimido. México: Siglo XXI editores, s. a de c. v.

Lozano, L. (2013). Patrimonio, Arte y Didáctica de las Ciencias Sociales. Análisis y reflexiones sobre una estrategia de aprendizaje en el marco de la innovación docente. Tarragona (España): Universitat Rovira i Virgili, pp, 1-18.

Ortuño J., Molina, S., Sánchez I \& Gómez C.J. (2012): El patrimonio en la escuela. La contribución del área de Didáctica de las Ciencias Sociales en España. En I Congreso Internacional de Educación Patrimonial: La Educación Patrimonial en España y Europa: pp 94-103

Reppeto, L. (2006) Memoria y patrimonio: algunos alcances - Organización de Estados Iberoamericanos. www.oei.es/pensariberoamerica/ric08a06.htm 
Reyes, J. Pupo, F. \& Jevey, A. (2003) La enseñanza de los valores patrimoniales en la enseñanza primaria en Cuba, en Patrimonio y didáctica de las ciencias sociales. Cuenca: asociación universitaria de profesores de didáctica de las ciencias sociales, pp. 135-141.

Hernandez, Sánchez, C. (2012): Ciudadanía, diversidad y participación, educar para la participación desde la diversidad. En Alba Fernández, N., García Pérez, F. F. y Santisestaban Fernández, A.: Educar para la participación ciudadana en la enseñanza de las Ciencias sociales. Díada: Sevilla. Volumen I Asociación Universitaria de Profesorado de Didáctica de las Ciencias Sociales, pp. 63-71

Zambrano, mM. \& Gnecco, C. (2000) Memorias hegemónicas, memorias disidentes. El pasado como política de la historia. Santafé de Bogotá, ministerio de culturaUniversidad del Cauca-Instituto Colombia de Antropología. pp. 184

UNESCO. (2002). Patrimonio y cultura local en la escuela, Santiago de Chile: http $/ /$ www.unesco.org/new/fileadmin/MULTIMEDIA/FIELD/Havana/pdf/laformac iondelaidentidadcultura.pdf

UNESCO. (1989). Recomendación sobre la salvaguardia de la cultura tradicional y popular. 15 de noviembre, http://portal.unesco.org/es/ev.phpURL_ID=13141\&URL_DO=DO_TOPIC\&URL_SECTION=201.html

Proyecto Aprendizajes Productivos a Través de la Comprensión Etnocultural. https://www.facebook.com/usctrab/videos/con_tactopedag\%C3\%B3gicoaprendizajes-productivos-a-trav\%C3\%A9s-de-la-comprensi\%C3\%B3netnocult/410768679945035/ 